\title{
Experience of Nursing Students \& Teachers on “E-Learning” During COVID-Lockdown-Qualitative Descriptive Study
}

\author{
Dash $M,{ }^{1 *}$ Jena $\mathbf{N}^{2}$ \\ ${ }^{1}$ Prof \& Head Department of OB \& GY Nursing, MTPG \& RIHS, India \\ ${ }^{2}$ Senor Sister Tutor. Nurses Training Institute, School of Nursing, India
}

\section{Abstract}

Background: COVID-19 is a disease caused by the "novel corona virus".In order to prevent transmission of this virus whole World was under Lockdown. This leads to teachers to go for online classes. This is unexpected change for students as well as to teachers.

Objectives:

- To explore the experience of the students \& teachers regarding online class

- To identify the Contributory factors and challenges faced by students and teachers

- To identify teaching strategies that will enhance online learning

Methodology:

Design- Qualitative Descriptive design

Sample and Sample Size- 87 Students and 46 teachers participated

Analysis \& Ethical Approval- Permission was obtained from the Institutional Ethical Committee.

Data was collected byonline survey \& interview during month of April 2020. The data were analyzed by qualitative content analysis. Three levels of coding were selected for coding the data.

The quantitative part of the data was analyzed with the help of descriptive statistics like frequency and percentage and presented in the form of tables.The Qualitative analysis presented as per the themes and subthemes.

Findings: The findings of the study identified four main themes1. Online class is very useful 2. Contributory Factors, 3. Challenges faced by students and teachers and 4. Quality of teaching-learning resources. Majority 83 (95.4\%) students reported that they had used time productively, 75(86.21\%) students reported that there was no face to face interaction, Internet Problem-connectivity 55(63.22), Financial problem to recharge mobile 25(28.74\%),67(77.01\%) students Suggested that they need Synchronous,requested to Include Viva questions 17(19.54\%)etc..

Conclusion and Implication: It is concluded from the results that students and teachers are generally ready to adopt e-learning. However, the results show that the current online class system is inadequate and improvement is required in certain areas so as to increase the efficiency and effectiveness of the e-learning as an educational tool.

Keywords: Experience, Online learning, Students, Lockdown, COVID

\begin{tabular}{|l|l|}
\hline \hline Quick Response Code: & *Corresponding author: Manjubala Dash, Prof \& Head Department of OB \& GY Nursing, \\
MTPG \& RIHS, Pondicherry, India \\
Received: 31 December, 2020 Published: 18 January, 2021 \\
Citation: Dash M, Jena N. Experience of Nursing Students \& Teachers on “E-Learning” During \\
COVID-Lockdown-Qualitative Descriptive Study. Trends Nur Health Care Res. 2021;1(1):1-9. \\
DOI: 10.53902/TNHCR.2021.01.000501
\end{tabular}




\section{Introduction}

COVID-19 is a disease caused by the "novel corona virus". COVID-19 spreads mainly by droplets produced as a result of coughing or sneezing of a COVID-19 infected person. This Disease spread rapidly too many through direct \& indirect contacts. ${ }^{1}$ The main and import measures to prevent spread of infection are based on 3 "S" that is maintaining Social Distancing, wearing masks and hand sanitation or hand wash. Hence to prevent spread of infection Govt. of India declared sudden complete lockdown in Whole Country. This unexpected lockdown leads to shutdown of the colleges, schools and all the shops...etc. Being a teacher of the Professional Course we are halfway in completing the syllabus. It's a great dilemma when the college will reopen and we will complete the syllabus. Beginning it was declared for 21 days from $24^{\text {th }}$ March to $15^{\text {th }}$ Aprilbut further extended to whole months. As soon as the lockdown declared our Authority called for meeting and asked all the staffs to start online mode of class for students, until we meet for physical classroom class. There started our Journey to online class than offline class. Being a teacher thoughit's not new to handle the technology like computer-based learning like preparing Power point presentations, sharing through mail, doing video presentations, audio recordings etc...still we the professional teachers' not fully competent enough handling technology i.e. handling online classes for large number of students in a synchronous platform.

Days are passed but lockdown still continuing and it forced the teachers, to complete the portions, to prepare the students for examinations, to maintain continuity in studies etcto adopt various tools, media for online class. There are various medias like Zoom, Google classroom, Google meet, WebEx, Microsoft team etc. Really at first it gave a big challenge for teachers to prepare the meetings. Sometimes it took nearly 5-7 hours to prepare for one day class and sometimes the whole day passes only in preparation as we are not a professional typist. Further the power cut, computer problem are the additional obstacles faced by teachers. There arises question in the mind of the author that "we being a teacher, getting salary struggling hard and preparing the content, sending in google classroom in time as per the schedule given but how much the students are utilizing these resources". Further in physical classroom we can have face to face interaction and during our presence also students don't concentrate and when in our absence we just send the content how far students use this? This intention made the researcher to take this study to explore the experience of students' and teachers' regarding e-learning and also the findings of this study will enhance the skills to improve in future

Teaching in online class gives an opportunity to create a more engaging, interactive experience for the students if we take full advantage of the available technology. Its true we cannot replicate the in-person back-and-forth of a classroom but encouraging students to utilize social media channels or set up virtual discussion groups to work together helps us tomimic that collaborative environment. These ultimately motivate students to succeed -- and allow them to turn to each other as they work through the material. In the $21^{\text {st }}$ century, online learning is regarded as one of the main media to deliver training and education resources, with the benefits in terms of cost-effectiveness, accessibility and up-to-date information. ${ }^{2-5}$

Lam J, et al. $^{2}$ conducted a study on "A Report on the Online Learning Experience of Students in Accounting Course" highlighted theresult that most of the students were satisfied with the provision of online course materials and students felt it madetheir study more flexible and accessible.

\section{Objectives}

- $\quad$ To explore the experience of the students regarding attending online class during lockdown

- $\quad$ To explore the experience of the teachers regarding preparing online class during lockdown

- $\quad$ To identify the contributory factors challenges faced by students and teachers

- $\quad$ To identify teaching strategies that will enhance online learning

\section{Methodology}

Qualitative, descriptive approach was adopted as the research method for this study. This study utilized both surveys and interviews. ${ }^{6}$ The survey instrument had 10 open ended questions related to experience of student's and teacher's about online class. Out of these eight question for getting students experience and 2 questions regarding teacher's experience. All the questions were developed by survey Monkey App, and also shared through online, like through mail and WhatsApp group. The questions were open ended like- how do u feel about lockdown and online classes? how do u feel about classes sent by your teacher? how you will rate online classes ( 5 as excellent and 1 as poor)? Whether u prefer online or offline class? Rationalize..., Any suggestion for future? what are the advantages and disadvantages of online class? Do u prefer or recommend online class for future?. There are two questions for teachers like as teachers how you feel to prepare online classes? What is your experience about online class and how you like to rate your own class?. Survey Instrument was created on $25^{\text {th }}$ of April and circulated to groups of students and teachers those who had online classes. Instructions were given on the top of the questionnaire regarding the purpose of the study and it was also explained that their answer can be anonymous and confidentiality will be maintained. Last Response received by $22^{\text {nd }}$ May 2020.

This survey was administered via an independent staff who had no teaching responsibility for those students being surveyed. This removed bias or fear from students that they should respond with what they thought the teaching staff would require and that their results would be completely anonymous so that no repercussion was experienced from providing negative feedback (that is, completing this survey was completely independent, not affect their result in exams). In addition to the survey data, interviews were conducted with 10 students and five teachers to consolidate the survey findings. The plain language statement and the informed consent form were presented to the students prior to the survey and before the interview. This survey was conducted among Nursing students and teachers only and those who had attended online classes and 
those teachers conducted online classes. Total 87 students and 42 teachers responded to the survey through Survey Monkey App via mail. The survey responses were entered into a Microsoft Excel spreadsheet for data analysis preparation. The interview results were analyzed using qualitative data analysis techniques.

\section{Data Analysis}

The data were analyzed by qualitative content analysis. The responseswere read and re-read by the Investigators and coding was done independently in order to bring reliability.Three levels of coding were selected for coding the data.

Level 1 coding -The investigators examined the data line by line and made codes

Level 2 coding -The investigators compared the coded data and categories were created after clustering the coded data resulted from condensing the leve1 coding.

Level 3 coding - A central theme was derived from the categories that emerged during coding.

The quantitative part of the data was analyzed with the help of descriptive statistics like frequency and percentage and presented in the form of tables. The Qualitative analysis presented as per the themes and subthemes.

\section{Result and Findings}

Eighty seven students and 42 teachers responded to the survey questions in this study. To consolidate the survey findings 10 students and five teachers were interviewed through WhatsApp video call. The findings of the Interview were summarized as "students presented that "students felt online period was very useful as they could continue their study due to this online classes. They were also happy with the course materials provided by the teachers. They were expressing difficulties with the internet connections and electricity issues. Few students finding difficulty to do assignments which they are not interested. Students felt online learning was much helpful for them to maintain continuity for their study so they can prepare well for their examinations. They also felt that due to online class they were learned how to use the technology and attend classes online, submit assignments in online platform etc."

Interview to the teachers found that "overall teachers were happy that they were learning new technology which was interesting but they expressed that online preparation consumes lots of their time so they could not do any other work. It was difficult for them who don't know about computer application".

The qualitative analysis revealed the emergence of four themes and each theme gave rise to 4-5 subthemes (Figure 1, Table 1)

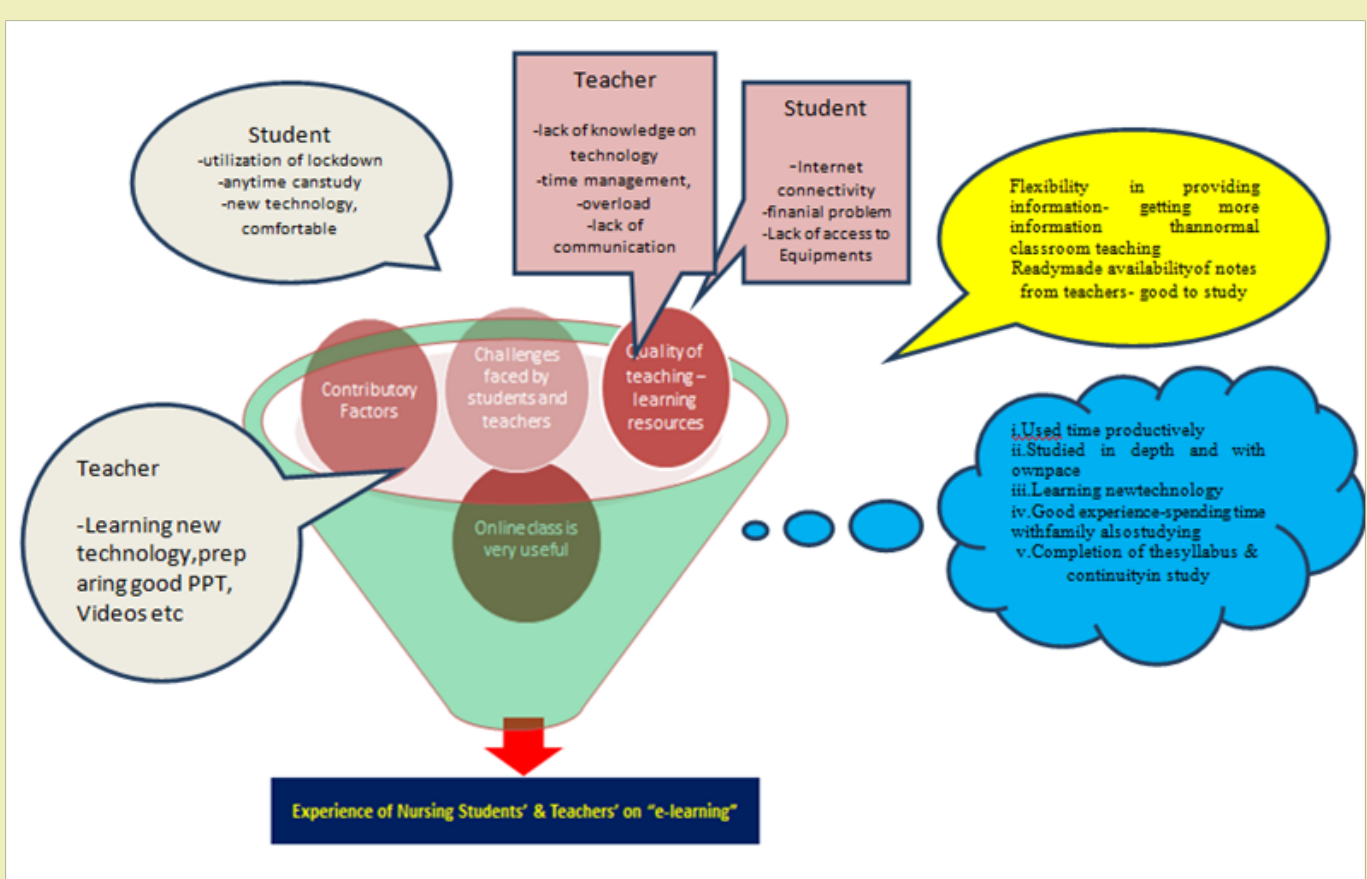

Figure 1: Emergence of four themes.

Table 1: The qualitative analysis of themes and subthemes.

\begin{tabular}{|c|c|}
\hline Theme & Sub Theme \\
\hline \multirow{4}{*}{$\begin{array}{c}\text { 1. Online class is very useful during this lockdown } \\
\text { period }\end{array}$} & i. Used time productively \\
\cline { 2 - 2 } & ii. Studied in depth and with own pace \\
\cline { 2 - 2 } & iii. Learning new technology \\
\cline { 2 - 2 } & iv. Good experience-spending time with family also studying \\
\cline { 2 - 2 } & v. Completion of the syllabus \& continuity in study \\
\hline
\end{tabular}




\begin{tabular}{|c|c|}
\hline \multirow[t]{5}{*}{ 2. Contributory factors by students } & i. Utilization of lockdown period \\
\hline & ii. Anytime can study-liberal learning \\
\hline & iii. Increase technical skills \\
\hline & iv. Comfortable environment \\
\hline & v. Self-discipline learning \\
\hline \multirow{2}{*}{ Contributory factors by Teachers } & i. learned new strategy -online app, preparation of good PowerPoint presentation, \\
\hline & ii.Trying to make class interesting-making different font color, adding animation, video show etc \\
\hline \multirow{4}{*}{ 3. Challenges faced by students } & Lack of support system- \\
\hline & i. Internet Problem-connectivity \\
\hline & ii. Financial problem to recharge mobile \\
\hline & iii. Nothaving access to mobile, computer or laptop, mobile repair, power cut etc \\
\hline \multirow{5}{*}{ Challenges faced by teachers } & i. Time management \\
\hline & ii. Feeling of Overload \\
\hline & iii. Difficult in handling technology \\
\hline & iv. Written test couldnot be conducted \\
\hline & v. Mostlyoneside- students are passive learner \\
\hline \multirow{5}{*}{ Challenges faced by Students \& teachers(Both) } & Lack of Teaching learning Resource- \\
\hline & i. No direct contact with Teacher(Face to face Interaction) \\
\hline & ii. Difficult to use black board \\
\hline & iii. Demonstration not possible \\
\hline & iv. inconvenience - continuous on screen leads to headache, irritation, loss of attention \\
\hline \multirow{2}{*}{ 4. Quality of teaching -learning resources } & Flexibility in providing information- getting more information than normal classroom teaching \\
\hline & Readymade availability of notes from teachers- good to study \\
\hline
\end{tabular}

Online class is very useful during this lockdown period- related to this theme all most all participants responded that online classes help them to learn and there is continuity for study. Few responses given by the participants are

a. "Social distancing is mandatory due to Covid pandemic and due to lockdown our study was disturbed but it was overcome by online class".(R-8)

b. "Online class is good compare to no class". (R-47)

c. "World does not stop to learn because of distancing, we got best knowledge through online class". (R-69)

d. "Very much useful and these are bestutilization of lockdown period"(R-11)

e. "Technology Helpful during the time of crisis"(R-80)

\section{A. Contributory factors for Students and Teachers}

With regard to contributory factors students responded that online classes are useful during lockdown period. Their some versions are given below.

i. "I am utilizing this lock down period so well so that no wastage of time."(R8)

ii. "I can study anytime and anywhere- Whatever lockdown but study have no lockdown". (R-22)

iii. “Using online class I have improved my technical Skill”(R-18)

iv. "I have touch with subjects". (R-30)
Related to this theme Majority of the teachers expressed that they are utilizing time effectively in preparation and they felt they are learning new strategies in teaching learning process. Some of their responses are-

I learned new strategy -online app, preparation of good PowerPoint presentation,

I am trying to make class interesting- making different font colour, adding animation, video show etc.

\section{A. Challenges faced by students and Teachers}

Though online class has improved use of technology skill still there are few challenges faced by students as well as teachers. Students faced difficulties are given below:

i. I don't have money to eat full meal per day, how can I recharge for mobile? As my parents are daily wages, due to lockdown no job "(p59)

ii. "I stay in village, so very poor internet connection, so many time I am missing the sessions"

iii. "many time power shutdown- give me trouble to work online"

With regard to challenges faced by teachers showed that all most all teachers had similar feelings like-

"I take minimum 5-6 hours for preparing one hour class, sometimes spending whole day- as we are not professional typist"(R10) 
"I am feeling overload of work, continuous sitting in the screen gives headache, eye pain etc,don't know how much students are utilizing but we are taking more pain"(R23)

"It is far better we can take class in the classroom compare to online class- as we don't see students when sharing the screen"(R27)

"Many time students not opening video and not mute their mike so creates extra sound, which is intolerable and we can't control and continue the class"(R37).

\section{Quality of teaching - learning resources}

Regarding this theme all most all the students were very happy about the content they are getting from their teachers. They feel lockdown time was properly utilized by doing online classes. Few responses are:

i. "I am getting more content from teachers now, which is so much useful for my study" (R51)

ii. Very good PowerPoint slides, so I am much interested to attend and as the teachers are sharing their PPT, it was useful to study anytime also repeatedly like how many times I want I can learn."(R70)

"All teachers are doing hard work to prepare for our classes and all teachers' content is good"(R7)

Further the quantitative analysis showed that out of 87 students 83 students responded to the question no1, 81 students responded to question no 2, 86 students responded to question no 3 , 84 students responded to the question no 4, 73 students responded to question no 5, 81 students responded to question no 6, 87 students responded to question no 7 and 87 (All) students responded to question no 8.

Regarding the question no $9 \& 10$ for Teachers total 42 teachers submitted their responses to the no 9 question and 28 teachers' submitted responses to the no 10 question.

The above Table highlights distribution of the students and teachers experience for online class. Regarding feelings of student's majority of the students $83(95.4 \%)$ reported that they had used time productively as classes are going on through online, so there is continuity in their study.

Regarding feelings about the classes most of the students $76(85.36 \%)$ responded that there is flexibility in the time for learning, like anytime, anywhere they can learn wheneverthey have interest and also they have expresses that they are getting more content as readymade notes through online class from the teachers which is more helpful for them to study.

Table 2a: Distribution of Responses by the students regarding experience about online classes $(\mathrm{N}=87)$

\begin{tabular}{|c|c|c|}
\hline \multicolumn{1}{|c|}{ Items } & Nercentage & 83 \\
\hline 1. How do you feel about lockdown and online classes & 95.4 & 83 \\
\hline i. Used time productively & 95.4 & 32 \\
\hline ii. Studied in depth and with own pace & 36.78 & 28 \\
\hline iii. Learning new technology & 32.18 & \\
\hline
\end{tabular}

In relation to rating the classes and the content provided by the teachers most of the students $30(36.78 \%), 32(34.48 \%)$ rated as 4 and 5 expressedas very good and excellent respectively.

With regard to preference for online or offline class majority $75(86.21 \%)$ students expressed that they were preferring only offline classes. The reason for interest towards offline class showed that majority $75(86.21 \%)$ students reported that there was face to face interaction between teacher and students. further $59(67.82 \%)$ students also expressed thatthere was better communication during offline class, $42(48.27 \%)$ students felt there was classroom experience, $33(37.93 \%)$ students reported offline class was more lively, $28(32.18 \%)$ reported that there was eye to eye contact between the teacher and student etc which made the class interesting and there was interest towards study. All most all the students $87(100 \%)$ expressed that they want online classes during lockdown period only.

Regarding Suggestion for the improvement of online class students reported that they need Face to face class (Synchronous) 67(77.01\%), requested to Include Viva questions 17(19.54\%), Include Quiz sessions, crossword, puzzles etc 5(5.75\%) which will keep them more alert and attentive throughout sessions and also suggested to Include online demo classes 5(5.75\%).

The responses regarding Advantages of online classes shows that students felt there was proper utilization of lockdown period 78(89.66\%), Anytime can study-liberal learning 14(16.1\%), Increase technical skills 66(75.86\%), Comfortable environment $23(26.44 \%)$, Self-discipline learning $16(18.39 \%)$ respectively.

The main disadvantages of online class felt by studentswere Internet Problem-connectivity 55(63.22), Financial problem to recharge mobile $25(28.74 \%)$, Not having access to mobile, computer or laptop, mobile repair, power cut etc $47(54 \%)$, No direct contact with Teacher(Face to face Interaction) 81(93.1\%), Difficult to use black board 18(20.69\%), Demonstration not possible 5(5.75\%), inconvenience - continuous on screen leads to headache, irritation,

With regard to preference for online class all most all students those who responded to this question reported that they need online class only during the period of lockdown to maintain social distance and to follow the norms of Govt.

Table $2 \mathrm{~b}$ presents the experience of teachers for preparing online classes highlights that all the teachers who responded $42(100 \%)$ felt that they had learned a new strategy, handling technology based classes as a contributory factor for teaching. loss of attention 58(66.67\%) etc. 


\begin{tabular}{|c|c|c|}
\hline iv. Good experience-spending time with family also studying & 35 & 40.23 \\
\hline v. Completion of the syllabus \& continuity in study & 20 & 22.99 \\
\hline 2. How do you feel the classes sent by teachers & 81 & 93.1 \\
\hline i. Flexibility in providing information- getting more information than normal classroom teaching & 76 & 85.36 \\
\hline ii. Readymade availability of notes from teachers- good to study & 23 & 26.44 \\
\hline 3. How will you give rating to classes( $1=$ poor to $5=$ Excellent $)$ & 86 & 98.85 \\
\hline 1 & 1 & 1.15 \\
\hline 2 & 4 & 4.6 \\
\hline 3 & 8 & 9.2 \\
\hline 3.5 & 7 & 8.04 \\
\hline 4 & 32 & 36.78 \\
\hline 4.5 & 3 & 3.35 \\
\hline 5 & 30 & 34.48 \\
\hline 4. Which mode is good- online/offline(rationlase)Offline is best due to & 84 & 96.55 \\
\hline i. Teacher can't be replaced & 15 & 17.24 \\
\hline ii. Direct students teacher Interaction & 75 & 86.21 \\
\hline iii. Good communication & 59 & 67.82 \\
\hline iv. More lively & 33 & 37.93 \\
\hline v. Use of blackboard & 26 & 29.88 \\
\hline vi. Classroom experience & 42 & 48.27 \\
\hline vii. Eye contact & 28 & 32.18 \\
\hline Online good only during lockdown period & 84 & 96.55 \\
\hline 5. Suggestions to Improve online class & 73 & 83.9 \\
\hline i. Face to face class(Synchronous) & 67 & 77.01 \\
\hline ii. IncludeViva questions & 17 & 19.54 \\
\hline iii. Include Quiz sessions, crossword, puzzles & 5 & 5.75 \\
\hline iv. Include online demo class & 5 & 5.75 \\
\hline 6. Advantages of online class & 81 & 93.1 \\
\hline i. Utilization of lockdown period & 78 & 89.66 \\
\hline ii. Anytime can study-liberal learning & 14 & 16.1 \\
\hline iii. Increase technical skills & 66 & 75.86 \\
\hline iv. Comfortable environment & 23 & 26.44 \\
\hline v. Self-discipline learning & 16 & 18,39 \\
\hline 7. Disadvantages of online class & 87 & 100 \\
\hline i. Internet Problem-connectivity & 55 & 63.22 \\
\hline ii. Financial problem to recharge mobile & 25 & 28.74 \\
\hline iii. Not having access to mobile, computer or laptop, mobile repair, power cut etc & 47 & 54 \\
\hline iv. No direct contact with Teacher(Face to face Interaction) & 81 & 93.1 \\
\hline v. Difficult to use black board & 18 & 20.69 \\
\hline vi. Demonstration not possible & 5 & 5.75 \\
\hline vii. inconvenience - continuous on screen leads to headache, irritation, loss of attention & 58 & 66.67 \\
\hline 8. Preference for online class in future & 84 & 96.55 \\
\hline Only during lockdown period & 84 & 96.55 \\
\hline
\end{tabular}

*all the responses ate multiple response, except the question for Rating the class. 
Table 2b: Distribution of Responses by the Teachers regarding experience about online classes $(\mathrm{N}=42)$

\begin{tabular}{|c|c|c|}
\hline Items & No & Percentage \\
\hline 9. As a teacher how you feel to prepare online classes & 42 & 100 \\
\hline \multicolumn{3}{|l|}{ 1. Contributory factors by Teachers } \\
\hline i. learned new strategy-online app, preparation of good PowerPoint presentation, & 42 & 100 \\
\hline ii. Trying to make class interesting-making different font color, adding animation, video show etc & 28 & 66.67 \\
\hline \multicolumn{3}{|l|}{ 2. Challenges faced by teachers } \\
\hline i. Time management & 42 & 100 \\
\hline ii. Feeling of Overload & 38 & 90.5 \\
\hline iii. Difficult in handling technology & 40 & 95.24 \\
\hline iv. Written test could not be conducted & 42 & 100 \\
\hline v. Mostlyoneside- students are passive learner & 42 & 100 \\
\hline vi. No direct contact with students(Face to face Interaction) & 42 & 100 \\
\hline vii. Difficult to use black board & 42 & 100 \\
\hline viii. Demonstration not possible & 42 & 100 \\
\hline ix. inconvenience - continuous on screen leads to headache, irritation, loss of attention & 42 & 100 \\
\hline 10. As teachers how you are rating your online classes & 42 & 100 \\
\hline 3 & 5 & 11.9 \\
\hline 4 & 30 & 71.43 \\
\hline 5 & 7 & 16.67 \\
\hline
\end{tabular}

*all the responses ate multiple response, except the question for Rating the class.

In relation to challenges faced by teachers for preparing classes all most all $42(100 \%)$ felt that time management not possible, written test could not be conducted, Mostly oneside- students are passive learner, No direct contact with students(Face to face Interaction), Difficult to use black board, Demonstration not possible,inconvenience - continuous on screen leads to headache, irritation, loss of attention etc and Majority of the teachers $40(95.24 \%)$ and $38(90.5 \%)$ represented that difficult to handle technology and its overload work for them respectively.

\section{Discussion}

The present study result highlights 4 main themes like 1 . Online class is very useful during this lockdown period, 2. Contributory Factors 3. Challenges faced by students and teachers and 4. Quality of teaching -learning resources.

The first theme - online class is very useful during lockdown period as all most all student felt as their time was properly utilized for study and there was continuity in studies too. The present study result was supported by Larry Ferlazzo ${ }^{8}$ on her article "What Students Are Really Thinking About Online Learning” one student Diana Lopez reported that "This new learning system has its perks,such as more time to do assignments in the comfort of your home, not having to wake up so early to go to school, and ensuring the safety of the staff as well as the students". Further added by another student EvelynnVang: "The online learning experience as a student for me has been fine. It's like I'll do the assignments whenever I feel like doing it".

Similar findings found by SakshiAgarwal and Jaya Shankar Kau$\operatorname{shik}^{4}$ in their study "Student's Perception of Online Learning during
COVID Pandemic" reported that "participants responded that these online sessions broke monotonous routine, were a good utilization of time and the material was easy to access. They felt motivated to read on those topics and it helped them not to think of COVID and sleep peacefully."

Further the findings also supported by Lam J, et al. ${ }^{2}$ conducted a survey on "Online Learning Experience of Students in Accounting Course" reported that most of the students were satisfied with the provision of online course materials which made their study more flexible and accessible. Online learning plays an important role in the learning process which allows learning to happen at anytime, anywhere.

Regarding the $2^{\text {nd }}$ theme on contributory factors for students' and Teachers' showed that all most all students' felt that online class is good as they can read anytime and radially available content. This result also supported by Brandi Ratcli ff, ${ }^{9}$ written an article on "Online Course Assessment" reported that students are fining easy to avail the course materials, classroom discussions. The course materials and activities may be accessed from any computer, whether it is from the University or from the comfort of your own home. Also online classes allow students to work on their own pace.

Further JianjunHou, Lingli Zhu, Haidi $\mathrm{Lu}^{10}$, in their article on "Instructor-led Online Learning at School of Distance Learning, Peking University" contributed that Self-regulated online learning provides a free and open learning environment so that the learners can arrange their learning process independently according to their own time and characters, which guarantee the self-regulation of learners. 
Further the teachers also felt online class was made them to learn about new technology. This result supported by Itika Sharma Punit ${ }^{7}$ reported in the article on"For many of India's teachers, online classes amid lockdown have been an awful experience",published on Scrool.in on $13^{\text {th }}$ May 2020.

Simon McIntyre, Dr Negin Mirriahi ${ }^{5}$ in their article on "Learning to Teach online" presented that The Internet has significantly changed how we communicate with one another as well as how we access, share and facilitate information. The issue is no longer one of how to use technology to teach, but one where teachers acknowledge the way the world is already developing, and understand the significance of online literacy and the role that collaboration and online engagement plays in student learning and their future workplace environment. Software and technology changes very rapidly, and it can be difficult to keep up with these developments. It is important therefore to focus on understanding effective pedagogical strategies for online teaching rather than the technology itself.

Third theme on challenges faced by students and teachers highlights that though there were some contributing factors simultaneously there were some challenging factors too which influenced students and teachers as well in their day to day teaching process. These findings also supported by other Researchers' finding likeAgarwalS, Kaushik JS 4"Most frequent factors hindering learning were stated as limitation on the number of participants, time limitation of the sessions, and technical faults during the conduct of sessions.

Larry Ferllazo ${ }^{8}$ in her article "what students are Really thinking about online Learning?" published on $12^{\text {th }}$ May 2020 in "Teachers Blog- Q \& A session" stated that student viewed online class as follows "Transferring to all online learning has been the biggest challenge this year for me. The biggest change I've seen in myself is becoming less focused with my school work. Being in a physical classroom is tremendously different from learning online. This online learning has affected me personally because during this time, I found myself turning in assignments weeks late. It wasn't because I was having trouble, it was because I had no motivation and energy to do them. Without a routine schedule, I felt lost. That makes me sound like a robot, but I think it's because it's been that way since we were so small, change this big is affecting me to the max."

Lee Xiong presented that: School has been tough. Transferring to all online learning has been the biggest challenge this year for me. As a student, I'd say I've usually kept up with all my work for all my classes. The biggest change I've seen in myself is becoming less focused with my school work.

Being in a physical classroom is tremendously different from learning online. In a classroom, most of your focus is there, unlike virtually, the temptations are REAL! Yes, self-discipline is good to learn, but when having all this thrown at you, you can't blame the student for not wanting to work... at least that's my opinion.

This online learning has affected me personally because during this time, I found myself turning in assignments weeks late. It wasn't because I was having trouble, it was because I had no moti- vation and energy to do them. This isn't the norm for me. Without a routine schedule, I felt lost. That makes me sound like a robot, but I think it's because it's been that way since we were so small, change this big is affecting me to the max.

This has taught me that online learning will not be for me in the future! Maybe for one or two classes, but overall I plan for my school life to be set in a physical classroom for the most part. Although this has been a challenging time for school and out in the real world, remembering to stand tall will get us through this together."

\section{EvelynnVang: "Learning at school is best for me"}

"I can say that there is a reason for this, and that is where I am doing my school work. My home is not a learning environment like at school, where there are teachers, other students, learning tools, desks/tables, chairs, a library, lots of space, and those who you can get support from. At home is like a sleeping or resting environment. In a classroom, I can focus more on my assignments/ work and get engaged in the subject. Whenever I'm in a classroom, I feel prepared to learn and get my brain pumped; at home, I feel like it's very hard to be prepared because I'm always getting distracted. Whenever I need help, my teachers or classmates are there for me. When I have a question at home, I have to wait for a response.From my online learning experience right now, I would not choose more online learning in the future because in a school, a classroom is a learning environment. Also, I feel like it's easier to communicate with my classmates/groups for projects, teachers, counselors, and principal. Learning at a school is best for me."

Challenges for Teachers highlights that online preparation consumes lots of time, difficult to learn technology and work overload. Findings of this present study supported by Itika Sharma Punit7, reported that various types of experiences shared by different teachers regarding online classes as follows:

"Saxena and Kumar are among the hundreds of teachers across the country who have been abruptly pushed into the uncharted "online classes" since India went into lockdown on March 25 in the wake of the Covid-19 pandemic."

"The syllabi of several national and international boards include skills that cannot be taught virtually, explained Shashi Banerjee, principal of Shiv Nadar School in Noida. "What we are missing out on [in online classes] is how the child is growing as an individual. If you look at a typical report card, it will assess communication skills, vocabulary, critical thinking, scientific aptitude," Banerjee said. These attributes are hard to assess remotely. "All this [virtual teaching] is okay for the short-term. If you're teaching and learning only through a device for the whole year, this is not how it's done."

For the fourth theme on quality of teaching learning resourcesstudents responded that materials were very useful and they were utilizing anytime anywhere also repeatedly reading whenever required. This finding supported by AgarwalS, Kaushik JS, ${ }^{4}$ conducted a study on "Student's Perception of online Learning during COVID Pandemic", reported that "Participants found the sessions to be relevant to their learning needs and clinical practice $[n=75(97 \%)]$. 
Majority of the participants perceived that the sessions were tailored to their level of learning $[n=76(99 \%)]$ and found the sessions to be interesting and enjoyable $[n=72(95 \%)] "$.

The above findings and from the suggestion by the students for online class the researchers planned to develop strategy for online learning which will be helpful for future teachers in order to make their class effective. These are as follows:

- Individualize Approach

- $\quad$ Mixed method of learning

- $\quad$ Synchronous class with variety

- Inclusion of alert sessions like quiz. Puzzle, short question and answers etc

- Demo videos etc.

\section{Conclusion}

COVID pandemic made us realize the importance of online training for our Nursing students. Apart from gain in knowledge, the present study revealed the impact of online learning on the morale of our students by creating a diversion from the ongoing pandemic situation. Software and technology changes very rapidly, and it can be difficult to keep up with these developments. It is important therefore to focus on understanding effective pedagogical strategies for online teaching rather than the technology itself.

The online instructor plays a vital role in developing and maintaining an effective online learningenvironment and must possess a unique set of tools to perform successfully. Some instructorsfrom the traditional classroom environment will easily adapt to the online model, while othersmay find the transition challenging. Reflect on your teaching style, circumstances and technicalskills to see if teaching online is right for us. ${ }^{11-15}$

It was concluded that online learning is useful for students and teachers except few limitations those can be overcome by empow- ering teachers with preparation skills. Today there are many online webinars arranged by different Institutions about online teaching strategy, different assessment tools to empower teachers further.

\section{Funding}

Self-Funded.

\section{Conflicts of interest}

None.

\section{References}

1. NHHRC data, Ministry of Health \& Family Welfare, Government of India, Role of Frontline workers in prevention \& management of Corona Virus, May 2020.

2. Lam J, Chan R, Yan K. A Report on the Online Learning Experience of Students in Accounting Course. In: Li KC, Wang FL, Yuen KS, Cheung SKS, Kwan R (Eds), Engaging Learners Through Emerging Technologies. ICT 2012. Communications in Computer and Information Science, Vol. 302, Springer, Berlin, Heidelberg, 2012, p. 31-44.

3. Reggie Kwan Fu Lee Wang (Eds.), Hybrid Learning: The New Frontier, $2^{\text {nd }}$ International Conference on Hybrid Learning- ICHL 2009, Macau, August, p. 25-27.

4. Agarwal S, Kaushik JS. Student's Perception of online Learning during COVID Pandemic, The Indian Journal of Paediatrics. 2020; 87(7):554.

5. Simon McIntyre, Dr Negin Mirriahi. "Why is online teaching important?" 2020.

6. Adam Jowett. Carrying out qualitative research under lockdown Practical and ethical considerations, Posted In: COVID 19 | Research methods, April $20^{\text {th }}, 2020$.

7. Itika Sharma Punit, For many of India's teachers, online classes amid lockdown have been an awful experience, published on Scrool.in on $13^{\text {th }}$ May 2020-1.30pm.

8. Larry Ferllazo. "what students are Really thinking about online Learning? Classroom Mnagement Q \& As: Expert Strategies for Teaching.

9. Brandi Ratcliff, Online Course Assessment, May 07, 2001.

10. Jianjun Hou, Lingli Zhu, Haidi Lu. Instructor-led Online Learning at School of Distance Learning, Hybrid Learning: The New Frontier, 2nd International Conference on Hybrid Learning- ICHL 2009, Macau, August 25-27, 2009, Selected Papers Peking University.

11. Joshua Sterm "Introduction to Online Teaching and Learning".

12. Strategies for Learning at a Distance.

13. What Makes a Successful Online Student?

14. Tips and Tricks for Teaching Online: How to Teach Like a Pro!

15. The Role of the Online Instructor/Facilitator. 